\title{
Estupro e gravidez: Relatos das vivências de mulheres antes e após o desfecho da gestação
}

Mykaella Cristina Antunes Nunes. Universidade de Fortaleza. Normanda Araujo de Morais. Universidade de Fortaleza.

\section{Resumo}

Investigou-se a experiência de três mulheres que engravidaram resultado de estupro, usuárias de um hospital-maternidade de Fortaleza, Ceará, destacando as vivências anteriores e após o desfecho da gestação (a continuidade ou a interrupção legal). Em dois casos houve a interrupção legal da gestação e em um caso a continuidade, após ter sido negada a concessão para a realização do aborto. Os motivos relacionados à interrupção da gravidez foram: pensamentos e sentimentos negativos em torno da violência, da criança e da perspectiva de vida futura. Após o desfecho, as participantes que interromperam a gestação expressaram o desejo de retomar ou iniciar projetos de vida e no caso da participante que precisou dar continuidade à gestação, sinais de uma possível vinculação afetiva com a criança. Conclui-se que tais experiências necessitam ser conhecidas em seus aspectos de interrupção ou de continuidade da gestação para a melhoria das políticas públicas voltadas para essas mulheres.

Palavras-chave: estupro; gravidez indesejada; aborto.

\begin{abstract}
Rape and pregnancy: Reports of the experiences of women before and after the end of pregnancy. We investigated the experience of three women who became pregnant by rape, using a maternity hospital in Fortaleza, Ceará, highlighting previous experiences and after gestation (continuity or legal interruption). In two cases there was a legal interruption of gestation and in one case continuity, after being denied the concession to perform the abortion. The reasons related to the interruption of pregnancy were: negative thoughts and feelings about violence, the child and the perspective of future life. After the outcome, participants who interrupted gestation expressed a desire to resume or initiate life projects, and in the case of the participant who had to continue gestation, signs of a possible affective attachment to the child. It is concluded that such experiences need to be known in their aspects of interruption or continuity of gestation for the improvement of the public policies directed towards these women.
\end{abstract}

Keywords: rape; unwanted pregnancy; abortion.

\section{Resumen}

Estupro e gravidez: Relatos de vivencias de mujeres antes y después del desfecho de la gestación. Investigue una experiencia de tres mujeres que graven el resultado de estupro, las usuarias de un hospital-maternidad de Fortaleza, Ceará, destacando como vivencias anteriores y después del desfecho de la gestación (una continuidad o una interrupción legal). En los casos en que se produjo una interrupción legal de la gestión y en el caso de una continuidad, después de haber sido negada una concesión para un acto de aborto. Los motivos relacionados con la interrupción de la gravedad son: pensamientos y sentimientos negativos en la violencia, de la infancia y la perspectiva de la vida futura. Tras el desfecho, como participantes que se interrumpen en una gestación expresada en el deseo de retomar o en iniciar los proyectos de vida y en el caso de la participación que precisan en la continuidad de la gestación, los signos de una posible vinculación afetiva con un niño. Conclui-se que tales experiencias necesitan ser conocidas en sus senos de interrupción o de continuidad de la gestación para un mejoramiento de las políticas públicas voltadas para estas mujeres.

Palabras clave: violación; embarazo no deseado; aborto. 
No Brasil, assim como em diversos países do mundo, a violência sexual (VS) representa um sério problema de saúde pública, constituindo-se como um dos principais indicadores da discriminação de gênero contra a mulher. Estudo realizado pelo IPEA (Instituto de Pesquisa Econômica Aplicada) acerca do estupro evidenciou que em relação ao total das notificações ocorridas em 2011, $88,5 \%$ das vítimas eram do sexo feminino (Cerqueira \& Coelho, 2014). A VS contra a mulher apresenta-se como uma das principais causas de morbidade e mortalidade feminina, com consequências psicossociais extremamente graves, afetando especialmente mulheres jovens em idade reprodutiva (Bedone \& Faúndes, 2007; Higa, Modaca, Reis, \& Lopes, 2008; Higa, Reis, \& Lopes, 2007). Entre as consequências da violência sexual, a gravidez se destaca pela complexidade das reações psicológicas, sociais e biológicas que implica. A gestação indesejada ou forçada é encarada como uma segunda violência, intolerável para muitas mulheres (Ministério da Saúde, 2012), fazendo muitas delas recorrerem a abortos clandestinos (Carvalho \& Paes; 2014; Wiese \& Saldanha, 2014).

A fim de assistir às vítimas de violência sexual, o Ministério da Saúde criou uma política de atendimento para as mulheres, vítimas de violência sexual, que prevê tanto o atendimento como a interrupção legal da gestação (ILG) nos casos de gravidez. Ela está organizada na Norma Técnica (NT) sobre "Prevenção e Tratamento dos Agravos Resultantes da Violência Sexual contra Mulheres e Adolescentes", criada em 1999 (Ministério da Saúde, 2012). A NT prevê total crédito ao relato da mulher, trazendo como principal inovação a não exigência da apresentação do Boletim de Ocorrência (BO) pela vítima de estupro para a realização de aborto legal. Este pode ser realizado até a $20^{\mathrm{a}}$ ou $22^{\mathrm{a}}$ semana de gestação e com o concepto pesando menos que $500 \mathrm{~g}$, não havendo indicação para a interrupção da gravidez após a $20^{\mathrm{a}}$ semana de idade gestacional. Nesse último caso, o que se prescreve são orientações sobre a adoção e sua facilitação. Para a realização da ILG faz-se necessário estar em conformidade com alguns procedimentos de acordo com a Portaria MS/GM n 1.508, do Ministério da Saúde, de $1^{\circ}$ de setembro de 2005 , que estabelece os Procedimentos de Justificação e Autorização da Interrupção da Gravidez nos casos previstos no âmbito do Sistema Único de Saúde (Ministério da Saúde, 2012).

Com relação aos casos de mulheres que engravidam após um estupro tem-se que as notificações dos casos ainda não condizem com a magnitude do problema. Muitas mulheres não chegam aos serviços de saúde por diversos motivos, entre eles por desconhecer a existência desses serviços e a política de atendimento voltada para as mulheres vítimas de VS; pelos sentimentos atrelados à vivência da VS, como o medo, a vergonha e o temor de se expor; pelas crenças de que serão julgadas e culpadas pela ocorrência da violência. Tal fato tem contribuído para o aumento de abortos clandestinos, realizados em contextos de precariedade e de risco para a saúde e vida dessas mulheres.

Quando conseguem chegar ao serviço de saúde tem-se observado que a maioria delas tem optado por interromper a gestação (Bedone \& Faúndes, 2007; Higa et al., 2007; Mattar et al., 2007). Contudo são poucos os estudos que tratam do acompanhamento dessas mulheres após a realização do aborto legal e/ou da continuidade da gestação, visto que nem sempre é dada continuidade ao acompanhamento dessas mulheres como sugere a NT (Ministério da Saúde, 2012). Tal acompanhamento seria de grande relevância, uma vez que se considera que tanto a interrupção legal da gestação como a continuidade da gestação, são eventos extremamente mobilizadores para a vítima de violência que engravidou decorrente de um estupro. Ambos (interrupção ou continuidade), portanto, geram consequências para a vida da mulher como um todo e, como tal, deveriam ser melhor acompanhadas pelas equipes de saúde.

Outro fator que justifica a necessidade de pesquisas nessa área refere-se à escassez de estudos que abordam a experiência de vida dessas mulheres. Em uma pesquisa de revisão sistemática da literatura (RSL), realizada pelas autoras desse artigo nas bases de dados IndexPsi, Scielo, LILACS e PsycInfo, foram localizadas apenas apenas seis produções na área.

Parte dos artigos identificados versavam sobre experiências de continuidade da gestação, mencionando os fatores que levaram as mulheres a tal decisão: os aspectos positivos e negativos na relação mãe/bebê; o manejo dos profissionais para com o caso e a sugestão de parto cesárea (Cantelmo, Cavalcante, \& Costa, 2011; González, Luengo, Caba, \& Molina, 1999; Moura, Silveira, \& Nogueira, 2001; Santos, 2012; Vertamatti et al., 2009). Apenas um estudo abordou sobre as experiências de mulheres que interromperam a gravidez, tendo destacado os fatores motivacionais indicados para isso: o repúdio pela gravidez; o vínculo da gravidez à violência; a lembrança da violência e do agressor; entre outros (Drezett et al., 2011).

O presente artigo, portanto, considera importante dar voz às experiências das mulheres, considerando os 
aspectos já expostos, de que as vivências que antecedem o desfecho da gestação e que sucedem são mobilizadoras de emoções, potenciais para modificações de vida, visto o acontecimento da violência/gravidez que requer lidar com questões como a violência e o agressor; os sentimentos de vergonha e de medo; a relação mãe/bebê; os valores de família; os projetos de vida, etc.. Dai a importância dos recursos internos (história prévia dessa mulher, valores, crenças e características pessoais, etc.) e recursos externos (rede de apoio familiar ou profissional, etc.) no enfrentamento da situação de gravidez e desfecho, além da realização de pesquisas na área para melhor poder contribuir com políticas públicas voltadas para essas mulheres. Desta forma, este estudo teve como objetivo conhecer a experiência de mulheres que engravidaram resultado de estupro, destacando as vivências anteriores e após o desfecho da gestação, a continuidade ou a interrupção legal.

\section{Método}

Utilizou-se um delineamento de estudo de casos múltiplos, uma vez que se investigou um fenômeno contemporâneo em profundidade e em seu contexto de vida real (Yin, 2010). Tal proposta consiste em uma estratégia de pesquisa pluralista do ponto de vista metodológico, uma vez que pode envolver dados qualitativos, dados quantitativos ou conjugar as duas perspectivas. A opção por essa forma de abordagem deveu-se ao fato de que esses estudos são percebidos como mais consistentes na compreensão de fenômenos complexos (Stake, 2003; Yin, 2010). Em se tratando do público deste trabalho, as mulheres grávidas em decorrência de estupro, utilizou-se tal metodologia pelo aprofundamento que dá a cada caso, respeitando a diversidade das experiências e por possibilitar uma amplitude das vivências ao apresentar caso por caso. As experiências das mulheres grávidas resultado de estupro são diversas, ricas de significados e merecem por isso ser descritas detalhadamente.

\section{Participantes}

Os participantes desta pesquisa foram três mulheres, Ana, Bruna e Clara, que engravidaram como resultado de um estupro e que deram entrada para assistência em saúde num hospital-maternidade da cidade de Fortaleza-CE. Ana, 20 anos, raça/cor parda, de religião católica, solteira, ensino médio completo e trabalhava na área de comércio/serviços. Bruna, 31 anos, raça/cor parda, de religião católica, solteira, ensino médio incompleto, também trabalhava na área de comércio/serviços. Clara, 27 anos, raça/cor parda, de religião evangélica, solteira, ensino superior incompleto e não estava trabalhando.

O hospital em que o estudo foi realizado tem como característica a assistência materno-infantil, destacando-se na rede municipal de saúde pela atenção secundária em ginecologia, obstetrícia e pediatria, e também por dispor do Serviço de Atenção à Mulher Vítima de Violência Sexual e Doméstica, sendo o único da rede municipal a realizar o procedimento de aborto legal. 0 fato da primeira autora do artigo trabalhar no hospital em que foi feita a pesquisa possibilitou maior alcance às participantes, como também ajudou no manejo das entrevistas, visto a mesma ter prática de atendimento às vítimas de violência sexual.

\section{Instrumento}

Utilizou-se um roteiro de entrevista semiestruturada, especialmente elaborado para esse estudo. Os aspectos investigados nas entrevistas diziam respeito a: como chegou ao serviço hospitalar; o que tem pensado e sentido; se contou para alguém o que lhe ocorreu; o que acha melhor pra ela (interromper ou continuar a gestação); se houve mudanças em sua vida; como avalia a decisão que tomou, se recebeu ajuda de alguém e quais os desejos que possui para o futuro. Foram realizadas no total cinco entrevistas com todas as participantes, sendo as suas falas representadas por nomes fictícios acompanhado da identificação da entrevista (um, dois, única), da seguinte forma: Ana-E1, Ana-E2, Bruna-EUn, Clara-E1 e Clara-E2.

Também foram utilizados dados documentais disponibilizadas pelo hospital, tais como as fichas de Notificação/Investigação Individual, de Dados Sociais e de Avaliação Psicológica e outros registros que diziam respeito ao atendimento da vítima. Esses documentos foram consultados para a construção dos casos, porém apenas após a realização das entrevistas, a fim de evitar possíveis "a prioris" com as informações.

\section{Procedimentos de Coleta de Dados}

Em dois casos (Ana e Clara) foram realizadas duas entrevistas. Estas se deram num primeiro momento, no hospital-maternidade já mencionado; e num segundo momento, após o desfecho, as participantes puderam ser entrevistadas em local de sua preferência (no caso de Ana deu-se no hospital do estudo e no caso de Clara numa universidade particular). O tempo entre a primeira 
e segunda entrevista no caso de Ana foi de 1 mês e 6 dias; e no caso de Clara foi de 1 mês e 19 dias. Em um caso (Bruna) houve entrevista única, em virtude de a participante já ter passado pelo hospital e por escolha da mesma a entrevista aconteceu no próprio hospital, tendo sido entrevistada cinco meses após da admissão no serviço hospitalar. Quanto à duração das entrevistas variaram entre 20 min. a 40 min., tendo sido todas gravadas e transcritas na íntegra.

Acerca dos critérios de seleção das participantes, estabeleceu-se inicialmente que seriam feitas duas entrevistas em momentos diferentes intercalados por 30 dias, considerando que não podia ser de imediato a alta, visto o restabelecimento da mulher nem tardar tanto em razão das dificuldades de localizá-la novamente. No entanto, em decorrência da reduzida chegada de mulheres grávidas resultado de estupro e do tempo limitado para a realização da pesquisa, convencionou-se que seriam contatadas mulheres que já haviam passado pelo serviço hospitalar, como foi o caso de Bruna. Também se definiu que as crianças e as adolescentes (12 anos completos até 18 anos incompletos, de acordo com o Estatuto da Criança e do Adolescente - ECA) seriam excluídas desse estudo, participando somente as mulheres com idade mínima de 18 anos completos em razão de questões éticas diferenciadas para menores de 18 anos.

Em dois casos (Ana e Clara) o convite para participar da pesquisa foi feito presencialmente e em um caso (Bruna) por telefone em virtude da mesma já ter passado pelo hospital. Nos três casos tomou-se muito cuidado quanto à forma de tocar no assunto da violência e quanto ao local de coleta da entrevista, de modo que as participantes se sentissem seguras e acolhidas, sendo realizadas em local reservado. O momento da entrevista foi marcado pela intensidade de sentimentos e de pensamentos correspondentes à violência e à gravidez, por vezes sendo necessário interromper a entrevista em virtude das participantes ficarem emocionadas.

\section{Procedimentos de Análise de Dados}

Realizou-se de forma indutiva, sendo que as categorias emergiram a posteriori, e foram discutidas com base na literatura da área. A análise dos dados baseou-se no método de Análise de Conteúdo (Bardin, 1977/1995), o qual segue as seguintes etapas: 1) a pré-análise - organização das temáticas através de leitura flutuante, hipóteses, formulação de hipóteses, objetivos e elaboração de indicadores; 2) a exploração do material - os dados são codificados a partir de unidades de registro; e 3) o trata- mento dos resultados e interpretação - aqui é realizada a categorização das temáticas a partir de classificações dos dados em acordo com suas semelhanças e por diferenciação. Portanto, trabalham-se as temáticas apresentadas no material do texto, estabelecendo categorias para sua interpretação. Nesta proposta metodológica, o foco recai sobre o conteúdo relatado, entendendo que o texto é um meio de expressão do sujeito, no qual o analista busca categorizar as unidades de texto (palavras, frases, personagens, etc.) que se repetem, inferindo uma expressão que as representem (Caregnato \& Mutti, 2006). Após a definição das categorias temáticas, os dados foram discutidos a partir de relações feitas com a literatura específica da referida área de estudo.

\section{Procedimentos Éticos}

A pesquisa atendeu às recomendações bioéticas para pesquisas com seres humanos no que diz respeito à Resolução 466/2012 do Conselho Nacional de Saúde (CNS). As participantes foram informadas sobre os princípios bioéticos, também sobre os objetivos e procedimentos do estudo quando convidadas para participar voluntariamente da pesquisa, tendo assinado o Termo de Consentimento Livre e Esclarecido - TCLE. Além disso, assegurou-se a assistência à participante da pesquisa, caso alguma necessitasse de apoio psicológico em virtude da memória de eventos emocionalmente tão mobilizadores. O presente trabalho foi submetido ao Comitê de Ética da Universidade de origem das autoras, tendo obtido aprovação desta instituição e do hospital pesquisado.

\section{Resultados e Discussão}

A análise de conteúdo das entrevistas foi organizada a partir de duas categorias temáticas, sendo uma acerca da experiência anterior ao desfecho da gestação, "Sobre interromper ou ter que dar continuidade à gestação" e a outra acerca das experiências de vida após o desfecho da gestação, "Sobre a vida de agora: sozinha ou com a criança".

\section{Sobre Interromper ou Ter que Dar Continuidade à Gestação}

Acerca das experiências que antecederam o desfecho da gestação, as mulheres relataram sobre a escolha por interromper a gestação, tendo acontecido em dois casos (Bruna e Clara); e sobre ter que dar continuidade à gestação, em um caso (Ana). Neste, a primeira escolha 
da vítima foi interromper a gestação, contudo esta foi negada em razão do tempo gestacional de 22 semanas superior ao máximo permitido, de até a $20^{\mathrm{a}}$ ou $22^{\mathrm{a}}$ semana de gestação e com o concepto pesando menos que 500g para a interrupção, de acordo com as orientações da NT "Prevenção e Tratamento dos Agravos Resultantes da Violência Sexual contra Mulheres e Adolescentes" (Ministério da Saúde, 2012).

Nos três casos as mulheres manifestaram o desejo de interromper a gestação, como indica os relatos abaixo, tendo alegado entre os principais motivos para a ILG: a forma violenta como aconteceu a gravidez, ou seja, contra a sua dignidade sexual; a presença de sentimentos e de pensamentos ruins advindos da situação de violência e da gravidez decorrente; a impossibilidade de dissociar a violência e o agressor da imagem da criança, o que poderia tornar-se uma experiência negativa para a criança também.

Porque a única coisa que eu queria era tirar essa criança e eu não posso mudar isso [...] Eu me senti muito mal. Eu sinto uma grande vontade de morrer. Era tudo que eu queria nesse momento. A única coisa que eu desejo era poder tirar. Mas já que não é possível, nada mais pode fazer. (Ana-E1)

O desespero assim de, de, assim, de não querer, de não querer de jeito nenhum [...] E assim uma coisa que eu ia olhar, que eu ia me lembrar, que eu não ia conseguir viver bem. Eu acho que eu não ia conseguir nem tocar nessa criança [...] Que aquilo ia me atrapalhar, que aquilo era uma coisa ruim, que aquilo era vergonhoso, que era um momento ruim. (Bruna-EUn)

Eu sinto que é uma coisa que eu não quero. Eu não me sinto grávida, eu não me sinto mãe, eu não me sinto mulher... Eu só sinto que foi um erro que aconteceu. Foi uma desgraça. Foi uma coisa muito ruim, mas que eu não... não quero levar isso pro resto da minha vida. É muito o que eu já vou ter que carregar... essas lembranças, esses pensamentos. (Clara-E1)

Eu não penso que seria uma coisa boa nem pra mim e nem pra esse ser de jeito nenhum. Pra esse ser eu penso até que seria pior porque ele iria ter que enfrentar um desprezo de alguém que não deveria desprezar, que deveria amar, deveria sentir coisas boas, afeto... como também de pessoas que pudessem tá ao redor né? (Clara-E2)

Aspectos semelhantes foram encontrados em estudo sobre as razões alegadas pelas mulheres para realizar o abortamento em casos de violência sexual
(Drezett et al., 2011). Os autores verificaram elementos de responsabilidade na decisão das mulheres ao não permitir nascer uma criança em ambiente que não lhe fosse favorável para o seu desenvolvimento, visto as ausências afetivas que poderia sofrer, como também o temor de dano social ou psicológico, em decorrência dos julgamentos por parte da sociedade. Também a revolta pela violação do direito da maternidade, o repúdio pela gravidez e a impossibilidade de mantê-la, visto a associação com a violência, sendo os fatores mais apontados como impeditivos para a continuidade da gestação.

Percebe-se que nenhuma das mulheres desejou incluir em seus projetos de vida o acontecimento da gravidez, com exceção do caso de Ana em que não houve alternativa. É importante destacar que apesar de existir uma política própria de atendimento às vítimas de violência sexual, inclusive sendo assegurado o direito à ILG nos casos de estupro e se assim desejarem, ainda existem diversos obstáculos desde a chegada ao serviço de saúde até a realização do atendimento em sua completude, leia-se a realização do aborto legal.

As participantes deste estudo somente buscaram o serviço de saúde após a constatação da gravidez e após terem tentado interromper a gestação por métodos clandestinos e não terem conseguido. Fato esse preocupante, visto que tanto a contracepção de emergência, quanto a concessão para a ILG estão previstas na NT para os casos de VS. Desta forma, chegaram ao serviço de saúde após as $72 \mathrm{~h}$ da ocorrência da violência, quando já não era viável a administração da contracepção de emergência. Supõe-se que o sentimento de vergonha, o medo de se expor e dos julgamentos estiveram entre os principais motivos para terem negligenciado os cuidados emergenciais pós violência sexual, os quais são recomendados pela NT (Ministério da Saúde, 2012).

Ao chegarem ao serviço hospitalar e serem atendidas, logo manifestaram o desejo pela ILG, contudo no caso de Ana que já se encontrava com 20 semanas, houve maior mobilização institucional para a situação da participante e a favor da continuidade da gestação, o que vale questionar até que medida a instituição é parcial neste processo de decisão. A realização da ILG ainda é vista de forma negativa pelos profissionais nos serviços de saúde, de forma que as mulheres ainda encontram muitas resistências no contato com eles; quer seja em relação ao tema violência sexual quer seja em relação à ILG. No entanto, há experiências positivas de apoio profissional, como verificado nos relatos das participantes, em relação ao suporte recebido durante essa fase da vida. 
Quando você tá assim numa coisa, que alguém te puxa assim. Foi assim um porto seguro. Eu me senti assim acolhida, me senti protegida. (Bruna-EUn)

Um hospital que realmente se preocupa com o paciente, do que ele tá precisando, do que ele quer [...] Ela ficava comigo [psicóloga]. Aí foi lá no outro leito conversar com a menina [...] Ela se preocupa, ela tá lá e tudo, ela não tava lá porque era o meu caso não, ela tava lá porque tava dando atenção para os pacientes. (Clara-E2)

Acerca da decisão pela ILG, as duas mulheres que tiveram como desfecho a interrupção da gestação mostraram-se convictas de que a escolha feita foi a correta, alegando que não conseguiriam lidar emocionalmente caso a gestação tivesse continuado, podendo ocasionar severas consequências, tais como suicídio e "estrago de vida" para si e para a criança. Esses resultados são semelhantes ao do estudo de Machado, Fernandes, Osis, e Makuch (2015).

Eu avalio assim que foi o melhor pra mim porque eu nunca quis, não queria, não tinha como um fiIho, eu tinha como uma coisa, então assim até que Deus me mostre que eu fiz errado eu acho que eu fiz certo. [...] Se tivesse ido adiante eu acho que eu tinha me matado porque eu não queria de jeito nenhum. (Bruna-EUn)

Foi uma decisão pensada [...] De verdade [...] Porque eu penso que certamente seriam duas vidas estragadas, a minha e a dessa, desse ser porque eu sei que eu nunca iria olhar pra essa pessoa, pra esse ser de um jeito carinhoso, de mãe, de alguém que quer bem, eu sei, eu não ia conseguir fazer isso [...] (Clara-E2)

Também não apresentaram sentimentos/pensamentos ambivalentes em relação à continuidade ou interrupção da gestação que pudessem suscitar dúvidas quanto ao desfecho da gravidez. Mostraram-se muito decididas a abortar e satisfeitas pela decisão que tomaram, como nos relatos: "Eu não me via numa situação diferente. Eu não conseguia me imaginar numa situação diferente" e "Então eu acho que pra mim foi o melhor que eu fiz". A respeito de Bruna, durante os atendimentos de psicologia no hospital sua decisão manteve-se a mesma, como nos registros de seguimento ambulatorial de Psicologia: "Está segura de sua decisão pela interrupção da gravidez e ciente de todos os riscos"; "Continua afirmando que a interrupção da gravidez é a melhor opção para ela". Sobre Clara não foi possível analisar as fichas do seu atendimento, visto que não foram encontradas.

\section{Sobre a Vida de Agora: Sozinha ou com a Criança}

A partir dos relatos das mulheres foram identificadas diferentes mudanças de vida após o desfecho dado à gestação. As participantes também expressaram perspectivas diferentes acerca do enfrentamento da violência e da continuidade da gestação, no caso da participante em que foi negada a ILG (Ana). Sobre os dois casos em que se deu a interrupção da gravidez (Bruna e Clara), observou-se uma tentativa pela vítima de deixar no passado a vivência da violência e seguir em frente, como também de retomar atividades anteriores e resgatar antigos planos e projetos.

No caso de Bruna, das três mulheres, ela foi identificada como a mais frágil emocionalmente no momento da entrevista pela pesquisadora. Seus relatos evidenciaram importantes comprometimentos deixados pela violência, principalmente no que diz respeito aos relacionamentos afetivos e vida sexual, como se constata a seguir.

É assim me relacionar com alguém eu ainda não tentei. Eu ainda tô muito fechada sabe. Às vezes assim até sinto vontade de me relacionar assim com alguém, de namorar e tudo, mas aí eu fico assim um pouco reservada com esse assunto [...] Às vezes eu sinto assim um certo, não sei se a palavra certa é assim nojo ou sei lá repulsa, sei lá... quando eu imagino que eu vou ter que ter uma relação com uma pessoa (Bruna-EUn).

Percebe-se que na participante em questão a principal área afetada foi a dos relacionamentos afetivos e sexuais, mas também há presença de ansiedade, como as lembranças intrusivas, flashbacks, sensações corporais que retornam afetando sua vida diária. $\mathrm{Na}$ esfera emocional, a violência sexual é capaz de produzir efeitos complexos e devastadores, sendo citados principalmente a ansiedade, depressão, perda da autoestima, transtornos do sono, culpa, vergonha, dificuldade de estabelecer relações interpessoais tendendo ao isolamento social, entre outros (Lordello \& Costa, 2014; Vertamatti et al., 2009). Além dos sintomas já referidos também se percebeu significativa fragilidade emocional ao abordar o assunto da VS, tendo a jovem se protegido através do silêncio, como no relato abaixo.

Hoje se... se eu não tocar no assunto, eu vivo normal [...] Assim eu me lembro muito raramente. Pra mim se ninguém comentar tá enterrado, pronto. Morreu o assunto. Morreu a história. Pra mim eu penso assim. (Bruna-EUn) 
Entende-se tal comportamento como uma estratégia protetiva e também defensiva de lidar com o acontecimento da violência. Fazendo isso a jovem evita entrar em contato novamente com a experiência da violência e todos os sentimentos e pensamentos desencadeados. Algo marcante nos relatos de Bruna foi a recorrência quanto a não querer lembrar-se do que aconteceu, que também diz sobre a sua fragilidade a respeito da vivência não superada ainda.

Já no que diz respeito à Clara verificou-se sinais importantes de superação e readaptação à rotina de vida, além de planos para o futuro, conforme relatado na sequência:

Tudo na minha vida tinha parado. Então depois que tudo isso passou. É como se fosse uma nova vida, em relação a fazer planos, a pensar na vida [...] Eu tenho pensado assim realmente só coisas boas, coisas né pra frente com relação à vida profissional, à vida em si. Tenho retomado sonhos que eu tinha, que eu tenho de mestrado, de estudar que é o que eu quero, então é isso que eu tenho encaminhado. (Clara-E2)

O modo positivo de ressignificar a violência e o abortamento repercutem em Clara a sensação de alívio, calma e também a impulsionam a retomar seus projetos de vida. Não foram identificados comportamentos de fuga que justifiquem o posicionamento de não fixar na violência, mas sim a confirmação de antigos sonhos que se fortaleceram em decorrência do acontecimento. Sugere-se que a existência de planos muito bem firmados, o apoio recebido pela irmã, com quem compartilhou a história da violência sexual e a acompanhou ao serviço hospitalar, bem como a sua religiosidade tenham sido essenciais para o modo como conseguiu lidar com as adversidades enfrentadas.

No caso de Ana, único caso em que aconteceu a continuidade da gestação, são significativas as mudanças emocionais da primeira entrevista para a segunda. Durante a primeira entrevista percebeu-se a angústia que a jovem apresentava em relação a ter que gestar e ter uma criança da forma em que foi concebida, como expresso no relato: "Eu sinto muito uma revolta. Se eu pudesse eu tiraria com minhas próprias mãos. Mas eu não posso. Eu não consigo aceitar. Cada dia fica mais difícil". No entanto, na segunda entrevista, realizada 1 mês e 6 dias após a primeira, Ana apresentou-se com pensamentos diferentes, relacionados à gravidez e à criança que gerava, como se verifica nos relatos adiante.
Mas eu vejo que aquela criança, ela não pediu pra estar ali. Ela não pediu. Ela não sabe como foi que aconteceu. Não foi culpa dela. Aí, agora eu comecei a entender isso. Aí tá sendo mais fácil, pra mim. Eu vejo tantas mães que tem seus bebezinhos, às vezes até tem pai, os pais abandonam, elas criam sozinhas e às vezes é a felicidade delas lá na frente, né? A criança. (Ana-E2)

Eu tava pensando em doar ela pra uma família, mas eu tava pensando e eu tava vendo que aquilo ali, eu não ia conseguir me desfazer dela. Eu ia ficar imaginando onde é que tava, como é que... Não ia ser uma coisa que você compra e você entrega. É uma parte do seu corpo, uma parte sua. Não tem como você se desfazer dela e pronto. Aí eu comecei a ver, perceber que eu não ia conseguir fazer uma doação... Aí eu comecei a... a olhar ela assim com carinho, tentar assim gostar mais, aí foi crescendo... (Ana-E2)

Mudou a minha forma de pensar pra algumas coisas. Porque antes eu nem, assim, eu nem imaginava a ideia de criar né... Aí quando é agora que tá crescendo, que fica mexendo na minha barriga, eu fico vendo coisinha de criança... Assim, a gente já começa a descobrir aquele amor que a gente achava que não ia descobrir nunca. [...] Eu fico assim, imaginando que... o que vai acontecer, como é que eu vou... é, como é que vai ser depois que nascer, fica passando muita coisa assim pela minha cabeça que na hora nem eu consigo mesmo responder, assim, pra mim, sabe? [...] A minha ansiedade é de... eu queria logo, que chegasse logo pra mim ver como é que vai ser depois que ele nascer, eu tenho muito medo das responsabilidades. (Ana-E2)

Percebe-se que as mudanças sinalizam para sentimentos de afeto para com a criança e de uma possível relação maternal a ser construída, que deixa transparecer quando ela relata suas preocupações em relação à criança, a questão do cuidado e da responsabilidade, suas ansiedades, demonstrando que seus pensamentos estão direcionados ao contexto da gestação e de seu futuro papel de mãe.

Um fator importante para essa mudança parece ter sido a aceitação da família de Ana quanto à sua gravidez, recebendo-a novamente em casa e apoiando daí por diante a gravidez. Também o apoio recebido pela equipe multiprofissional enquanto permaneceu no hospital e após, através de acompanhamento ambulatorial, tendo sido significativos para pensar sobre sua nova condição de vida e para ampará-la nesse momento delicado. 
Tem me dado apoio que eu pensei que eu não teria <risos>. Eu imaginava tudo menos que eles [família] iam aceitar e iam me ajudar. Foi totalmente sem esperar. Hoje eu vejo que todo mundo tá se unindo pra, unindo todos pra poder ajudar pra poder ser da forma melhor. (Ana-E2)

Foi como se fosse uma família mesmo pra mim naquele momento. Tava tudo tão difícil [...] Foi, me acoIheram [profissionais], né... Não me julgaram. Me deram tudo que eu precisava, sem me cobrar nada. (Ana-E2)

No entanto, no relato de Ana, também foi possível identificar aspectos que apontam o sofrimento em relação às mudanças provocadas em sua vida em decorrência da violência e da gravidez, tais como nos relatos:

É que eu acho mais ruim mesmo é que, assim, eu não queria que mudasse... Eu gostava tanto da forma que era. Eu vejo que tá tudo mudado. Não quero dizer que sejam coisas ruins, mas são mudanças que eu tô sendo obrigada a aceitar. Não foi uma mudança que eu quis, que eu queria, que eu pensava agora. [...] Assim... porque eu vejo que é uma coisa que eu não posso dizer mais que não aconteceu... aconteceu e eu não posso interferir ... eu acho que aquilo ali vai tá na minha vida pra sempre. Eu achei uma forma mais fácil assim, de aceitar tudo que aconteceu. (Ana-E2)

As três experiências apontam para mudanças diferentes na vida das mulheres, com repercussões negativas na qualidade dos relacionamentos afetivos e outras desordens emocionais. Também com consequências mais positivas como a tentativa de resgatar o tempo perdido através de projetos profissionais, visto a sensação de estagnação da vida quando ainda grávida; e, a construção da maternidade com significantes de mais adequação a essa experiência, apesar da circunstância abusiva que a originou e das interrupções em atividades antes realizadas.

\section{Considerações finais}

O artigo buscou conhecer a experiência de mulheres que engravidaram resultado de estupro, destacando as vivências anteriores e após o desfecho da gestação, a continuidade ou a interrupção legal da gestação. Entre as mulheres entrevistadas, duas escolheram pela ILG e uma teve que dar continuidade à gestação após ter sida negada a autorização para o aborto legal.

Acerca das experiências que antecederam o desfecho da gestação, as mulheres relataram os motivos pelos quais desejavam interromper a gestação, destacando a vinculação da imagem da criança à lembrança da violência e do agressor; a ausência de sentimentos positivos em relação à criança; o peso emocional e social à vida da vítima e da criança; a intrusão de sensações negativas (lembranças, sensações corporais) no que diz respeito à violência; e, a falta de perspectivas de vida caso dessem continuidade à gestação. No que se refere aos acontecimentos posteriores ao desfecho da gestação, as mulheres referiram estar buscando retomar seus projetos de vida e superar a vivência da violência.

Já sobre o caso em que foi dada a continuidade da gestação percebeu-se a transformação de sentimentos e pensamentos por parte da jovem em relação à gravidez e à criança, tendo passado de um estágio de rejeição para outro que sugere maior aproximação afetiva à criança, expressa em preocupações que dizem respeito às necessidades da criança e ao desempenho do papel materno.

Acredita-se que a relevância deste estudo está em apresentar as experiências das mulheres vítimas de VS que engravidaram, considerando que são poucos os estudos que abordam as falas das mulheres. É importante, ainda, destacar a importância da rede de apoio familiar e profissional no enfrentamento da violência/ gravidez/desfecho, uma vez que se trata de uma situação extremamente mobilizadora física e emocionalmente e para tal é preciso suporte. A experiência de escutá-las ao longo da realização dos procedimentos, assim como dias após dar-se o desfecho, deixou muito clara a importância dessa escuta e suporte às mesmas.

Ainda ressalta-se o fato deste trabalho apresentar concomitantemente experiências de interrupção e de continuidade da gravidez, proporcionando uma maior diversidade de aspectos acerca da vivência das mulheres a partir da riqueza/complexidade do discurso das participantes, somente tendo sido encontrado trabalho com estudo de caso único e segundo a percepção dos profissionais. No entanto, recomendam-se mais pesquisas na área, como estudos de seguimento longitudinal após a decisão da vítima, para avaliar aspectos tais como relação mãe/filho (a), saúde mental materna, relações familiares e sociais, dependendo do desfecho escolhido. Também são importantes estudos de avaliação do atendimento por elas recebido a fim de proporcionar maior compreensão sobre as experiências das mesmas e consequentemente promover melhorias nas políticas de saúde, sobretudo àquelas direcionadas à gravidez advinda de estupro. 


\section{Referências}

Bardin, L. (1995). Análise de conteúdo. (L. Reto \& A. Pinheiro, Trads.). São Paulo: Martins Fontes (Obra original publicada em 1977).

Bedone, A. J., \& Faúndes, A. (2007) Atendimento integral às mulheres vítimas de violência sexual: Centro de Assistência Integral à Saúde da Mulher, Universidade Estadual de Campina. Cadernos de Saúde Pública, 23(2), 465-469. doi: 10.1590/S0102-311X2007000200024

Cantelmo, C., Cavalcante, T., \& Costa, L. (2011). A menina mãe: incesto e maternidade. Fractal: Revista de Psicologia, 23(1), 137-154. doi: 10.1590/S1984-02922011000100010

Caregnato, R. C. A., \& Mutti, R. (2006). Pesquisa qualitativa: análise de discurso versus análise de conteúdo. Texto Contexto Enfermagem, 15(4), 679-84. doi: 10.1590/S0104-07072006000400017

Carvalho, S. M., \& Paes, G. O. (2014). As experiências de mulheres jovens no processo do aborto clandestino - uma abordagem sociológica. Saúde e Sociedade, 23(2) 548-557. doi: 10.1590/ S0104-12902014000200015

Cerqueira, D., \& Coelho, D. S. C. (2014). Estupro no Brasil: uma radiografia segundo os dados da Saúde. Brasília: IPEA.

Drezett, J., Pedroso, D., Gebrim, L. H.; Matias, M. L., Macedo Júnior, H., \& Abreu, L. C. (2011). Motivos para interromper legalmente a gravidez decorrente de estupro e efeitos do abortamento nos relacionamentos cotidianos das mulheres. Reprodução \& Climatério; 26(3): 85-91. Recuperado de http://www.sbrh.org.br/sbrh_novo/ restrito/revista/2011_jul_set_85-91.pdf

González, E., Luengo, X., Caba, F., \& Molina, T. (1999). El contexto sociofamiliar de los hijos de madres adolescentes cuyos embarazos fueron consecuencia de violación. Cuadernos Médicos Sociales, 40(2), 25-32. Recuperado de http://cms.colegiomedico.cl/Magazine/1999/40/2/40_2_7.pdf

Higa, R., Mondaca, A. D. C. A., Reis, M. J., \& Lopes, M. H. B. M. (2008). Atendimento à mulher vítima de violência sexual: protocolo de assistência de Enfermagem. Revista da Escola de Enfermagem da USP, 42(2), 377-382. doi: 10.1590/S0080-62342008000200023

Higa, R., Reis, M. J., \& Lopes, M. H. B. M. (2007). Interrupção legal da gestação decorrente de estupro: assistência de enfermagem às mulheres atendidas num serviço público da cidade de
Campinas - SP. Ciência, Cuidado \& Saúde, 6(3), 372-376. doi: 10.4025/cienccuidsaude.v6i3.1747

Lordello, S. R., \& Costa, L. F. (2014). Gestação decorrente de violência sexual: um estudo de caso à luz do modelo bioecológico. Contextos Clínicos, 7(1), 94-104. doi: 10.4013/ctc.2014.71.09

Machado, C. L., Fernandes, A. M. S., Osis, M. J. D., \& Makuch, M. Y. (2015). Gravidez após violência sexual: vivências de mulheres em busca da interrupção legal. Cadernos de Saúde Pública, 31(2), 345353. doi: 10.1590/0102-311X00051714

Mattar, R., Abrahão, A. R., Neto, J. A., Colas, O. R., Schroeder, I., Machado, S. J., ... Bertolani, G. B. M. (2007). Assistência multiprofissional à vítima de violência sexual: a experiência da Universidade Federal de São Paulo. Cadernos de Saúde Pública, 23(2), 459-464. doi: 10.1590/S0102-311X2007000200023

Ministério da Saúde. (2012). Prevenção e tratamento dos agravos resultantes da violência sexual contra mulheres e adolescentes: norma técnica ( $3^{\mathrm{a}}$ ed). Brasília: Ministério da Saúde.

Moura, E. R. F., Silveira, L. C., \& Nogueira, R. A. (2001). A realidade do abuso sexual na vida de uma adolescente: relato de caso. Revista da Rede de Enfermagem do Nordeste, 2(1), 15-19. doi: 10.15253/ rev\%20rene.v2i1.5798

Santos, A. P. (2012). Violência sexual infantojuvenil: problematizando os desafios do atendimento a partir da análise de um caso clínico. Mental, 10(18), 89-108. Recuperado de http://pepsic.bvsalud.org/ scielo.php?script=sci_arttext\&pid=S1679-44272012000100006\&ln $\mathrm{g}=\mathrm{pt} \& \operatorname{lng}=\mathrm{pt}$

Stake, R. E. (2003). Case studies. In N. K. Denzin \& Y. S. Lincoln (Orgs.), Strategies of qualitative inquiry ( $\left.2^{\mathrm{a}} \mathrm{ed}\right)$ (pp. 134-164). Thousand Oaks, California: Sage.

Vertamatti, M. A. F., Souza, J. V. L., Vieira, S., Ohata, A. P., Sancovski, M., Abreu, L. C., \& Barbosa, C.P. (2009). Parto cesárea em gravidez decorrente de estupro. Revista Brasileira de Crescimento e Desenvolvimento Humano, 19(2), 327-331. doi: 10.7322/jhgd.19922

Wiese, I. R. B., \& Saldanha, A. A. W. (2014). Aborto induzido na interface da saúde e do direito. Saúde e Sociedade, São Paulo, 23(2), 536547. doi: 10.1590/S0104-12902014000200014

Yin, R. K. (2010). Estudo de caso: planejamento e métodos (4a ed.). Porto Alegre: Bookman.

Mykaella Cristina Antunes Nunes, Mestre em Psicologia pela Universidade de Fortaleza (UNIFOR), é Doutoranda em Psicologia pela Universidade de Fortaleza (UNIFOR) e Bolsista da Fundação Cearense de Apoio ao

Desenvolvimento Científico e Tecnológico (Funcap). Endereço para correspondência: Universidade de Fortaleza, Programa de Pós-graduação em

Psicologia. Av. Washington Soares, 1321, Edson Queiroz, CEP: 60.811-905, Fortaleza, CE. Telefone: (85) 3477-3219. E-mail: mykaellanunes@hotmail.com

Normanda Araujo de Morais, Doutora em Psicologia pela Universidade

Federal do Rio Grande do Sul (UFRGS), é Professora do Programa de

Pós-Graduação em Psicologia da Universidade de Fortaleza (UNIFOR) e Bolsista de Produtividade II do CNPq. E-mail: normandaaraujo@gmail.com

Recebido em 28.Jan.16 Revisado em 26.Dez.16 Aceito em 31.Dez.16 